\title{
LEADERSHIP COMPETENCIES BASED ON GENDER DIFFERENCES AMONG ACADEMIC LEADERS FROM THE PERSPECTIVES OF FACULTY MEMBERS: A SCENARIO FROM SAUDI HIGHER EDUCATION
}

\author{
Omaymah Radwan ${ }^{a^{*}}$, Ahmad Zabidi Abdul Razak ${ }^{a}$, Simin Ghavifekr ${ }^{a}$ \\ ${ }^{a}$ Department of Educational Management, Planning \& Policy, \\ Faculty of Education, University of Malaya \\ *Corresponding Author's Email: omaymahradwan@gmail.com
}

\begin{abstract}
This study aims to identify the level of academic leadership competencies in selected Saudi higher education institutions (SSHEIS). It also seeks to investigate gender differences in academic leadership competencies $(A L C)$ in SSHEIs. This study employed quantitative method to collect the data. The researchers used a questionnaire consisting of 29 items. The questionnaire was randomly distributed among faculty members in the SSHEIs in Jazan Province. There were 550 questionnaires distributed, 496 of them were received for analysis using SPSS (V.23). The data were analysed using descriptive statistics and an independent sample T-test. The findings indicated that academic leaders had a very high level of leadership competencies $(L C)$ which reflect on the very high level of personal skills (PS) and high level of required skills (RS) of academic leaders. The findings also revealed that there is a significant gender difference in the mean score regarding the $A L C$ in higher education. The findings implied that male academic leaders had more LC compared to female academic leaders. The current results are valuable for higher education in terms of providing evidence of the level of $L C$ and gender differences of leadership competencies in the SSHEIs. Accordingly, the findings will contribute to the body of knowledge regarding leadership in higher education. The findings also will be beneficial for policymakers, academics leaders, and the officials of higher education. The theoretical and practical implications of the study as well as recommendations were also discussed.
\end{abstract}

Keywords: Leadership Competencies, Academic Leaders, Saudi Higher Education, Gender Differences

\section{INTRODUCTION}

The success of higher education depends on strong leadership. Earlier studies emphasised that leadership in an educational environment is one of the most vital components in terms of making positive differences in management (Al-Safran, Brown, \& Wiseman, 2014; Balwant, 2016; Day, Gu, \& Sammons, 2016; Pina, Cabral, \& Alves, 2015). Leadership in higher education plays a significant role in achieving desirable outcomes and improving the educational environment (Karavidić, Karavidić, \& Vujičić, 2016; Shahmandi, Silong, \& Ismail, 2012). Additionally, Shahmandi et al. (2012) pointed out that the competency of academic leaders plays a significant part in producing a satisfactory environment for faculty to teach successfully, so that there can be excellence educational outcomes for students. This infers that academic leadership is an essential factor in higher education management. Based on that, several studies examined and identified the competencies required for academic leaders in higher education and how these competencies have led to desirable outcomes (Albutti, 2014; Alhojeli, 2010; Cukanovic-Karavidic et al., 2016; McDaniel, 2002; Smith \& Wolverton, 2010, Spendlove, 2007; Sydänmaanlakka, 2003). Some of 
these studies highlighted that the high level of LC is attributable to a highly qualified graduate who can improve the social and economic growth. The quality of higher education depends on academic leaders who have the right level of LC. Therefore, they have to improve their level of LC to help their universities to survive in the competitive environment (Shahmandi et al., 2012). They need to achieve a particular level of leadership competency to help them succeed in higher education.

Saudi higher education is one of the sectors that play a crucial role in developing the country by providing qualified individuals from different specialisations (Albutti, 2014; Alshayea, 2012). They are also responsible for improving and renewing individuals' knowledge and skills for innovation and creativity. Therefore, Saudi higher education is in dire need of qualified academic leaders with the required level of LC to hold important leadership positions. However, minimal studies are conducted in Saudi Arabia to identify the competencies of academic leaders (Albutti, 2014; Almaki, Silong, Idris \& Abd Wahat, 2016; Hallinger \& Hammad, 2019; Hammad \& Hallinger, 2017; Radwan, Abdul Razak, \& Ghavifekr, 2020). There were only a few studies that identified leadership competencies of academic leaders in Saudi higher education (Albutti, 2014; Almaki et al., 2016; Radwan et al., 2020). Indeed, there were also only a few studies that compared gender differences of academic leadership positions in Saudi Arabia (Albutti, 2014; Almaki et al., 2016). Generally, there were not many studies done about leadership in higher education in many countries (Bellibas, Özaslan, Gümüs, \& Gümüs, 2016; Gmelch, 2013; Radwan et al., 2020). The current investigation found a gap in the literature where there are still no systematic strategies of the ALC in Saudi higher education. There is also no particular level of academic leadership competency in Saudi Higher Education. Therefore, the current study is aimed at filling this gap by identifying the level of the ALC at SSHEls. It is also aimed at comparing gender differences in the ALC of the SSHEls.

Accordingly, this study focuses on higher education institutions with the following objectives:

1. Identify the level of academic leadership competencies in terms of their personal skills (PS) and required skills (RS).

2. Examine gender differences in the mean score of academic leadership competencies in terms of their PS and RS.

\section{THEORETICAL FOUNDATION}

\section{Leadership Competencies}

The competency concept has several meanings, and it differs from one researcher to another and from one organisation to another. These differences in meaning are based on the type of organisation that has the various requirements of skills and knowledge of individuals (Albutti, 2014; Seemiller, 2016). However, the competency concept has a common theme. It refers to the skills, knowledge, behaviours, motives, abilities, attitudes and other characteristics of the individuals (Albutti, 2014; Spencer \& Spencer, 1993; Seemiller, 2016). McClelland (1973) was the founder of the concept of competency. He pointed out that competencies can be described well as an iceberg. The top of the iceberg contains the skills and knowledge of the individuals, while the hidden part under the waterline of the iceberg covers the characteristics of individuals such as self-confidence, empathy, traits, motives, self-concepts, and other personal characteristics. The competency skills and knowledge are easy to develop compared 
to other personal competencies such as motives, traits, or attitudes (Spencer \& Spencer, 1993). The concept of competencies can be related to leadership. Several researchers referred to LC as leadership skills that contribute to the significant performance of any organisation (Albutti, 2014; Ngowi, 2017).

McClelland's concept of competency paves the direction for the theorists and psychologists to develop a number of theories and models regarding LC. The Pyramid of Leadership or the Leadership Competency Model is one of the models which were developed based on McClelland's concept (Clark, 2016). The Pyramid of Leadership developed by Clark is divided into 3 main stages: Core Competencies that present the PS, Leadership Competencies that display the RS, and Professional Competencies. The first stage of the pyramid is core competencies which represent the PS of the leader. This stage is considered the foundation of the pyramid that holds the remaining parts of the pyramid together. At this stage, the PS covers communication, teamwork, interpersonal skill, self-direction, creative problem-solving, management of client relationships, flexibility, financial control, the formation of appropriate relationships, business acumen, and professionalism.

The second stage of the leadership pyramid is Leadership Competencies which represent the RS of leaders. The skills at this stage are leadership abilities, creating team, leading teams, implementing employee involvement strategies, visioning process, improving conflict resolutions, managing project, assessing situations quickly and accurately, and training assistants and subordinates. The final stage of the pyramid of leadership is professional competencies for the training of leaders. It shapes the mortar that links the pyramid together. It covers the aids, skills, and knowledge required for leaders to direct the system. The competencies covered in this stage are having the RS for consultation, adult learning, instructional design, rapid design, and instruction (Clark, 2016). The theory of Leadership Competency suggests that skills, knowledge, personal characteristics are vital factors for a competent leader. It was pointed out that leaders who follow the level of skills in the pyramid of leadership regularly end up being active leaders in the workplace (McClelland, 1973; Vazirani, 2010). This confirmed the idea that competencies are strongly associated with workplace performance.

Additionally, transformational and transactional leadership theories are some of the leadership methods used to develop LC in higher education. Adams and Md Yusoff (2019) mentioned that transformational leadership aims to foster capacity building and help individuals in educational environment to increase their effort and productivity. Besides, Carless, Wearing, and Mann (2000) highlighted that LC could be measured based on transformational and transactional leadership behaviours. Therefore, Carless et al. (2000) stated that the competencies of leadership could be assessed by applying the Multifactor Leadership Questionnaire (MLQ) developed by Bass and Avolio (1994). The MLQ is focused on measuring the competencies (skills of leaders) based on transformational and transactional leadership. Studies have implied that transformational and transactional leadership have positive effects and desirable outcomes in the educational and academic settings (Alfraih, 2014; Al-Safran et al., 2014; Balwant, 2016; Day et al., 2016; Leithwood, Patten, \& Jantzi, 2010; Pina et al., 2015). Therefore, the current study applied the MLQ, which focused on transformational and transactional leadership to evaluate the competencies of academic leaders (skills) in higher education. 
Transformational Leadership approach has become the most popular source in leadership research (Majeed, Mohd Nor, \& Mohd Mustamil, 2017). It is also relevant to both higher education and leadership domains. The transformational theory focuses on the relationship between a leader and the followers. For example, leaders tend to improve the motivation and morale of the followers (Northouse, 2016). Several manners are included in transformational theory, namely, individualised consideration, motivation, idealised attributes, intellectual stimulation, inspirational, and behaviours (Yukl, 2013). Implementing the features of transformational leadership theory will allow academic leaders to be more productive and competent and capable of leading successfully.

The transactional theory is also one of the effective theories in leadership. Some of the academic leaders focused on improving the performance through rewards or punishments of the subordinates (Sultana, Darun, \& Liu, 2015; Northouse, 2016). The transactional leadership theory is useful in the event of crisis and emergency. The style of reward and punishment is found to be effective in the educational environment. Academic leaders who adopt transactional theory not only do they want to ensure that there is work quality but also to achieve quality in higher education. Other theories and instruments in leadership can also be useful in measuring LC (skills). For instance, the Leadership Trait Questionnaire (LTQ) (Northouse, 2016), the Skill Inventory (Northouse, 2016), and the Authentic Leadership Questionnaire (ALQ) (Walumbwa et al., 2008) are valid measurements and instruments that can be used to assess leadership skills in educational environments.

\section{Level of Academic Leadership Competencies in Higher Education}

The LC is very crucial for academic leaders because competencies help them to achieve the desired outcomes and performance of higher education (Albutti, 2014; Alhojeli, 2010; Shahmandi et al., 2012; Smith \& Wolverton, 2010; Spendlove, 2007). Therefore, academic leaders in higher education must obtain the right level of the LC in order to lead higher education effectively (Shahmandi et al., 2012). The level of competencies differs from one study to another and from one researcher to another.

Several studies which were conducted to identify the level of LC concluded with noteworthy results. A quantitative study was conducted by Shahmandi et al.'s (2012) to examine the relationship between the level of competencies and the effectiveness of academic leaders at 4 research universities in Malaysia. The study focused on exploring whether the gender of academic leaders is associated with the effectiveness of leadership and whether there is a difference between level of competencies, gender, and leadership effectiveness. The findings indicated that the level of competencies has a significant impact on leadership effectiveness. Also, it was revealed that gender does not affect the effectiveness of leadership. The results also established that the relationship between the ALC level and gender does not have a significant effect on leadership effectiveness. The findings pointed out that the level of the LC is ranked high to moderate at the research universities in Malaysia. Besides, there is no low level of competencies with academic leaders, because the results indicated that the high-level of the ALC was $78 \%$, while the moderate level was $22 \%$. This study highlighted that identifying the level of the ALC in higher education is very vital to achieving effectiveness in higher education. It helps determine the leadership development needs for academic leaders. 
Similarly, a study was conducted by Trettel (2011) to examine the level of leadership skills of mid-level administrators at community colleges in Pennsylvania, USA. The researcher also explored how these leadership skills are related to the LC as recommended by the American Association of Community Colleges (AACC). The results indicated that the level of competency was above average, which ranges from 2.64 to 3.66. It showed that the LC of mid-level administrators was associated with the AACC. Meanwhile, Alhamdi (2000) conducted a study in Yemen to identify the level of performance (leadership skills) of heads of departments, or 10 deans from Sanaa University. The results indicated that the overall leadership skills of academic leaders were below average. This is because most of the deans at Sanaa University had little leadership skills. The study recommended that the leaders should have vision in undertaking their roles and responsibilities, as it was extremely necessary for academic leaders to have a vision for an outstanding leadership.

Meanwhile, academic leaders at Saudi higher education faced many challenges. This includes lack of a proper guideline or leadership competency model that could help them achieve the required success in the workplace (Albutti, 2014). There were limited studies about ALC in higher education in Saudi Arabia (Albutti, 2014). A study conducted by Albutti (2014) in Ha'il University, Saudi Arabia, focused on identifying the ALC of departmental heads. Albutti studied the competency skills which are required by academic leaders and degree qualifications. The researcher analysed the LC of the respondents using different statistical methods in acquiring the competencies according to their experience, kind of college, and academic rankings. The findings also highlighted that there was no statistical difference between respondents who had degree of $L C$ and academic ranking. On the contrary, there was a statistical difference between the degree holders of LC and its significance to the type of college they worked. Based on that, Albutti's (2014) study clarified that the level of respondents with the ALC in selected Saudi Higher Education (Ha'il University) was very high. Therefore, most of the previous studies claimed that there was no lowlevel of ALC in higher education.

\section{Gender and Leadership Competencies}

Gender is considered as a multidivisional concept that refers to diverse responsibilities, role, and experience of the individuals (male or female) (Eklund, Barry, \& Grunberg, 2017). It was operationalised by observing the performance of male and female. Although cultural biases always interpret the competencies based on gender, it is not a central feature of competency. It must be judged regardless of gender. Eklund et al. (2017) cited that the role of gender affects the role of leadership in the organisation. Gender is also related to leadership style and effectiveness. Although Eklund et al. (2017) stated that gender is associated with the effectiveness of leadership, nevertheless Shahmandi et al.'s (2012) pointed out that gender of leadership does not have a significant effect on the efficiency of leadership.

However, Connerley, Mecham, and Strauss (2008) conducted a study to examine the role differences play by a man or a woman in assessing the insights of global competence. The findings indicated that females were rated lower than males for expatriate positions which are usually dominated men. Although male supervisors participated in this rating, there were no differences in the general performance of both sexes. Similarly, Samuel and Mokoaleli (2017) carried out a study in South Africa that examined the causal relationships between employees' insight of both managerial and practical competencies of male and female managers. The results 
show that male managers were more competent than female managers. However, Samuel and Mokoaleli, (2017) finding was disputed by Donnell and Hall (1980) who stated that there was no difference between men and women in terms of managerial competency. Powell (1990) agreed with Donnell and Hall (1980) and pointed out that the differences reported between male and female in management were based on a stereotype. However, in the light of that, Arditi, Gluch and Holmdahl (2013) reported that their study identified some differences in the competencies between men and women. Indeed, Tomal and Jones (2015) stated that the differences in competencies reflect the historical insights regarding male and female managers and leaders. Besides, Nieva and Gutek (1981) highlighted some previous studies that focused on gender differences in leadership role which showed that a male is perceived as better suited than a female. In fact, most of the earlier studies cited that male leaders are more competent than female leaders.

\section{The Current Status of Studies Related to Academic Leadership Competencies and Gender Differences in Saudi Higher Education}

Based on the literature review above, ALC did not receive much attention from scholars in the context of higher education (Bellibas et al., 2016; Radwan et al., 2020). There was still lack of investigations regarding $\mathrm{LC}$ in terms of the personal and required skills of academic leaders in Saudi Higher Education (Albutti, 2014; Radwan et al., 2020). There was also a scarcity of studies regarding gender differences of the ALC in Saudi Higher Education (Albutti, 2014; Almaki et al., 2016). The researchers found a gap in the literature as there are still no systematic strategies, guidelines, or framework of ALC in Saudi higher institutions of learning. Therefore, the present study was conducted to fill this gap and to identify the level of LC of academic leaders in Saudi Arabia. Figure 1 below shows the conceptual framework of this study.

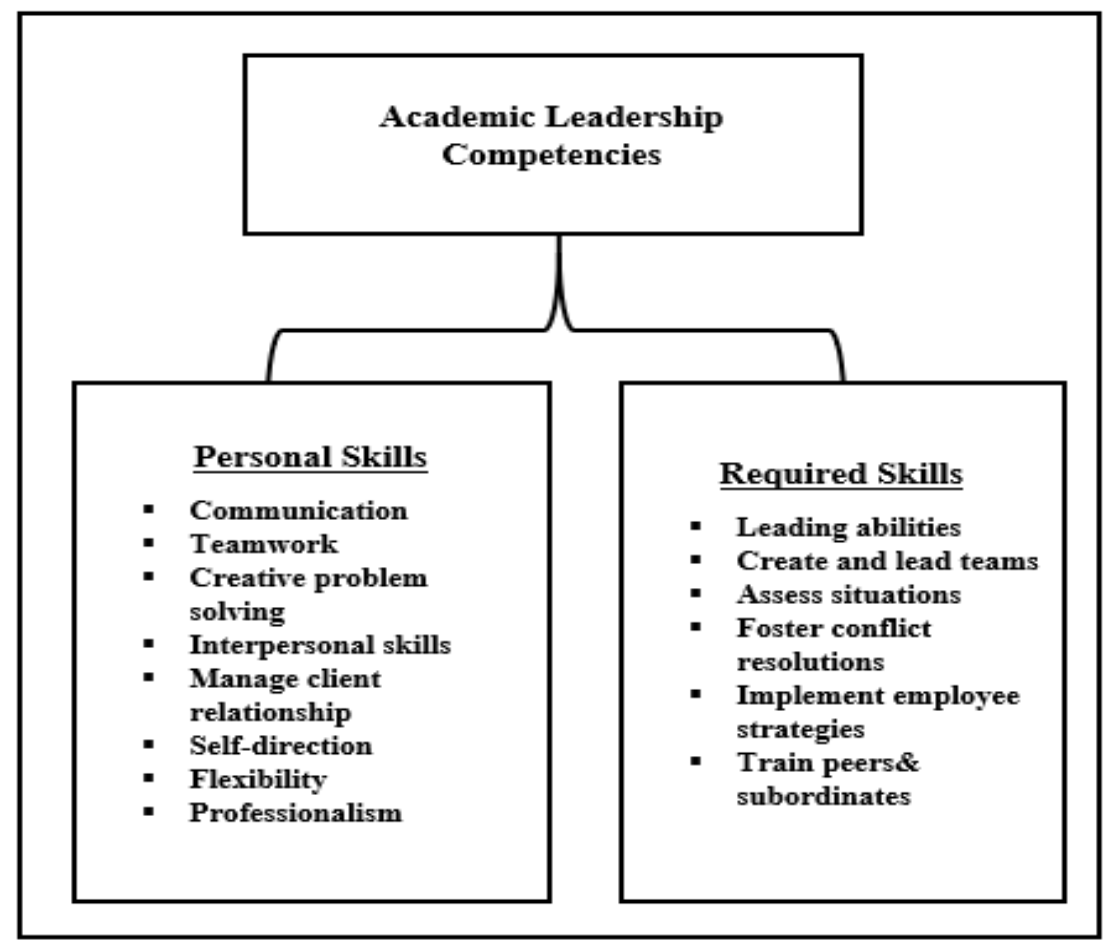

Figure 1. Conceptual framework of the study.

Source: Bass \& Avolio, 2004; Carless et al., 2000; Clark, 2016; Northouse, 2016; Walumbwa et al., 2008). 
As shown in the conceptual framework above, the LC is gauged by measuring the personal and required skills of academic leaders. Several instruments were used to measure academic leaders' skills which were adopted from (Bass \& Avolio, 2004; Carless et al., 2000; Clark, 2016; Northouse, 2016; Walumbwa et al., 2008). Accordingly, the current study seeks to answer the following questions:

1. What is the level of the ALC in terms of their PS and RS in the SSHEIs?

2. Is there a significant gender difference in the mean scores for the ALC in terms of their PS and RS in the SSHEIs?

Two hypotheses were formulated to answer Question No. 2 as follows:

$\mathrm{H}_{1}$ : There is a significant gender difference in the mean scores of the ALC in terms of their PS in the SSHEIs.

$\mathrm{H}_{2}$ : There is a significant gender difference in the mean scores of the ALC in terms of their RS in the SSHEIs.

\section{METHODOLOGY}

The current study adopted a quantitative research methodology. The following section provided more details regarding this methodology, including study's design, population, sampling technique, and instrument development that covers the validity and reliability of the instruments. This was followed by the data analysis using the Statistical Package for Social Science (SPSS) (V. 23).

\section{Design}

The current study used a survey design by applying the cross-sectional design and collected data through the distribution of a questionnaire on the targeted population. Creswell and Creswell (2017) stated that the cross-sectional designs used to collect data about opinions, beliefs or even current attitudes. Since the present study focuses on collecting data from the opinion and the perspectives of faculty members and investigating the current situation of leadership competencies, the cross-sectional design is the most suitable design for this study.

\section{Population}

The data were collected from the perspectives of faculty members who worked in higher education institutions in Jazan province. Compared to other provinces in Saudi Arabia; the researchers selected Jazan province for conducting this study for several reasons. It has 2 different institutions of higher education including a research university (Jazan University (JU) which had 3431 faculty members) and technical colleges (Technical and Vocational Training Corporation (TVTC) with 397 faculty members). Both institutions consisted of 30 colleges, 111 departments and 3 institutes. It has a large number of faculty members (targeted population) around 3828. It has a remarkable economy city compared to other provinces which is estimated to have 500.000 new jobs opportunities for graduated students (Royal Commission for Jubail \& Yanbu, 2019).

Hence, higher education in Jazan Province is responsible for producing highly qualified graduates who contribute to the economic growth in the province. Higher education in Jazan is in dire need of competent academic leaders with a high level of leadership 
skills and competencies to achieve the desired outcomes. Therefore, there is a need for conducting this study in Jazan province to investigate the current situation and provide the necessary recommendations to the officials. Since Saudi Higher Education institutions share similar features, and are controlled by the Ministry of Education, the findings can be shared with institutions in other provinces in Saudi Arabia (Saudi Ministry of Education, 2019). Accordingly, the targeted population was faculty members in Jazan higher education who were counted to 3828. The data was collected from the perspectives of the faculty members who are considered as educators and academic staffs at the colleges and universities. They are a group of people who are responsible for teaching students and enforcing the organisation rules (Rafique, 2014). The faculty members included in this study were professors, lecturers and researchers at Jazan University and technical colleges. They were selected to participate in this study because they have a direct relationship with both academic leaders (heads of departments) and students, and they also exert direct and indirect effects on the higher education system.

Based on the sample size determined by Krejcie and Morgan (1970), the minimum sample size for a population of $\mathbf{3 8 2 8}$ members should not be less than 350 faculty members (Chua, 2016). Creswell and Creswell (2017) pointed out that it is favourable to collect a large sample of the population to avoid potential error in data analysis. Therefore, the current study received more than 350 responses after applying random sampling technique. This technique provides a chance for every individual in the population to be selected in the study.

\section{Instrument}

The questionnaire used for this current study contains 29 items which was adopted from several instruments (Bass \& Avolio, 1994; Northouse, 2016; Walumbwa et al., 2008). It has 3 main sections. The first section includes the demographic information of the participants, which covers their age, gender, type of institutes, years of experience, and their specialisation. The second section includes items which measured the level of ALC that focused on the PS. The section on the PS covers 13 items adopted from different instruments including the Leadership Trait Questionnaire (LTQ) (Northouse, 2016), the Skill Inventory (Northouse, 2016), the Authentic Leadership Questionnaire (ALQ) (Walumbwa et al., 2008). The third section includes items which measured the level of ALC. It focused on the RS, which contains 16 items adopted from the Multifactor Leadership Questionnaire (MLQ) (Bass \& Avolio, 1994). Carless et al. (2000) cited that MLQ can be used to measure the competencies of leadership.

Therefore, this section adopted the MLQ from Bass \& Avolio (1994), which was a validated instrument to measure the skills of leadership (Northouse, 2016). The instruments utilised a 5-point Likert scale and participants were asked to select only one response for each item according to $1=$ Strongly Disagree, $2=$ Disagree, $3=$ Neutral, 4=Agree, or 5= Strongly Agree. A pilot test was conducted to test the reliability and validity of the instrument. The pilot study was conducted on the 150 responses first. It was a pilot study before the actual study to alert the researcher regarding the potential problems that may occur during the data collection and analysis (Creswell \& Creswell, 2017; Chua, 2016). This was conducted from March to April 2019. After receiving the 150- clear responses, a preliminary test was performed to measure the validity and reliability of the questionnaire as follow. 


\section{Validity}

After consulting with four different experts who are specialists in the field of higher education and leadership, the instrument was validated based on recommended criteria. Their comments were used to improve the questionnaire. The factor analysis was also applied to determine the validity of the 29 items. The Kaiser Meyer-Olkin (KMO) and Bartlett's Test of Sphericity were used to test data factorability. The KMO was above 0.6 and considered an acceptable value, as suggested by Pallant (2013) and Kaiser (1974). The Bartlett's Test was also significant $(p<0.05)$ and acceptable, as indicated by Pallant (2013) and Bartlett's (1954). Therefore, the factor analysis is considered appropriate.

\section{Reliability}

Reliability measures the internal consistency of the instrument using Cronbach's Alpha coefficient (Pallant, 2013). The acceptable value of the Cronbach's alpha was from 0.70 to 0.95 (Tavakol \& Dennick, 2011). Table 1 below shows the results of the reliability test.

Table 1: Reliability Test

\begin{tabular}{ccc}
\hline Factors & Number of Items & Value of Cronbach's Alpha \\
\hline Personal Skills (PS) & 13 & .955 \\
Required Skills (RS) & 16 & .930 \\
\hline
\end{tabular}

The table above shows that the PS contains 13 items and recorded an acceptable value of Cronbach's alpha of 0.955 . The RS covers 16 items and reported an acceptable value of Cronbach's alpha of 0.930. These values are acceptable based on the values suggested by Tavakol and Dennick (2011). Based on the results and discussion above, the current instrument is a reliable and valid instrument that was used for the actual study. The findings of the real study are presented in the following sections.

\section{FINDINGS}

\section{Demographic Information}

The demographic information of the participants is presented in Table 2 below.

Table 2: Demographic Information

\begin{tabular}{lccc}
\hline Demographic Item & Categories & Frequency & Percentage \% \\
\hline \multirow{2}{*}{ Institute } & JU & 339 & 68.3 \\
& TVTC & 157 & 31.7 \\
\hline \multirow{2}{*}{ Gender } & Male & 228 & 46.0 \\
& Female & 268 & 54.0 \\
\hline \multirow{3}{*}{ Age } & $20-30$ & 101 & 20.4 \\
& $31-40$ & 257 & 51.8 \\
& $41-50$ & 107 & 21.6 \\
\multirow{2}{*}{ Years of Work } & Over 50 & 31 & 6.3 \\
Experience & Less than 5 Years & 187 & 37.7 \\
& From 6-10 Years & 177 & 35.7 \\
& From 11-15 Years & 67 & 13.5 \\
& Over 15 Years & 65 & 13.1
\end{tabular}


Field

$\begin{array}{ccc}\text { Technical Training } & 154 & 31.0 \\ \text { Engineering } & 40 & 8.1 \\ \text { Social Science } & 30 & 6.0 \\ \text { Arts \& Humanities } & 65 & 13.1 \\ \text { Science } & 79 & 15.9 \\ \text { Health Science } & 50 & 10.1 \\ \text { Applied Science } & 31 & 6.3 \\ \text { Others } & 47 & 9.5\end{array}$

The table 2 above shows that the majority of the respondents (68.3\%) were from Jazan University (JU) compared to the respondents of the TVTC (31.7\%). The female respondents (54.0\%) outnumbered the male respondents (46.0\%). Majority of the respondents' (51.8\%) age ranges from 31 to 40 years old. Most of the respondents had more than five years of work experience. Finally, the field of science achieved more percentage $(15.9 \%)$ of the respondents compared to other fields at $\mathrm{JU}$, while the technical training field got the highest rate $(31.0 \%)$ of respondents from TVTC. Based on the findings, most respondents were from $\mathrm{JU}$, and the largest proportions of the respondents were female.

\section{Level of Academic Leadership Competencies}

The first objective was focused on identifying the level of academic leadership competencies. To achieve this objective, descriptive statistics were applied using the SPSS, which concentrates on the overall mean score of the respondents. The overall mean indicates a level of agreement from the respondents (Hair, Hult, Ringle, \& Sarstedt, 2017). Table 3 below presents the results of the descriptive statistics.

Table 3: Descriptive Statistics of ALC

\begin{tabular}{|c|c|c|c|c|c|c|c|c|}
\hline LC & & $\begin{array}{l}\text { SD } \\
\text { (\%) }\end{array}$ & $\begin{array}{c}D \\
\text { (\%) }\end{array}$ & $\begin{array}{c}\mathrm{N} \\
\text { (\%) }\end{array}$ & $\begin{array}{c}A \\
(\%)\end{array}$ & $\begin{array}{l}\text { SA } \\
\text { (\%) }\end{array}$ & Mean & StD \\
\hline \multirow{13}{*}{ PS } & PS1 & 0.2 & 1.2 & 5.2 & 32.7 & 60.7 & 4.52 & .672 \\
\hline & PS 2 & 0.4 & 3.0 & 10.3 & 51.4 & 34.9 & 4.17 & .762 \\
\hline & PS 3 & 0.2 & 4.4 & 11.3 & 40.9 & 43.1 & 4.22 & .831 \\
\hline & PS 4 & 0.0 & 1.2 & 4.2 & 55.2 & 39.3 & 4.33 & .615 \\
\hline & PS 5 & 0.2 & 2.4 & 10.7 & 47.2 & 39.5 & 4.23 & .751 \\
\hline & PS 6 & 0.0 & 1.8 & 5.6 & 52.8 & 39.7 & 4.30 & .659 \\
\hline & PS 7 & 0.0 & 1.6 & 6.3 & 41.3 & 50.8 & 4.41 & .682 \\
\hline & PS 8 & 0.0 & 4.0 & 11.9 & 43.8 & 40.3 & 4.20 & .802 \\
\hline & PS 9 & 0.2 & 2.2 & 9.1 & 46.6 & 41.9 & 4.28 & .735 \\
\hline & PS 10 & 0.0 & 3.2 & 6.3 & 47.2 & 43.3 & 4.31 & .729 \\
\hline & PS 11 & 0.0 & 1.2 & 4.8 & 43.3 & 50.6 & 4.43 & .645 \\
\hline & PS 12 & 0.0 & 0.8 & 9.9 & 44.4 & 45.0 & 4.33 & .685 \\
\hline & PS 13 & 0.0 & 0.0 & 2.2 & 48.0 & 49.8 & 4.48 & .543 \\
\hline \multicolumn{2}{|c|}{ Total of PS } & & & & & & 4.32 & .700 \\
\hline \multirow{2}{*}{ RS } & RS 14 & 0.8 & 2.2 & 12.5 & 32.9 & 51.6 & 4.32 & .837 \\
\hline & RS 15 & 0.2 & 1.6 & 5.8 & 55.8 & 36.5 & 4.27 & .660 \\
\hline
\end{tabular}




\begin{tabular}{cccccccc}
\hline RS 16 & 0.2 & 1.6 & 9.7 & 45.4 & 43.1 & 4.30 & .724 \\
RS 17 & 0.0 & 1.8 & 7.9 & 54.0 & 36.3 & 4.25 & .673 \\
RS 18 & 0.2 & 2.6 & 11.1 & 42.9 & 43.1 & 4.26 & .773 \\
RS 19 & 0.2 & 2.6 & 12.5 & 49.4 & 35.3 & 4.17 & .757 \\
RS 20 & 0.2 & 1.4 & 8.1 & 46.6 & 43.8 & 4.32 & .700 \\
RS 21 & 0.0 & 0.6 & 13.9 & 48.8 & 36.7 & 4.22 & .696 \\
RS 22 & 0.4 & 3.4 & 13.9 & 43.5 & 38.7 & 4.17 & .820 \\
RS 23 & 0.0 & 2.6 & 10.3 & 50.4 & 36.7 & 4.21 & .729 \\
RS 24 & 0.6 & 3.2 & 10.9 & 43.1 & 42.1 & 4.23 & .814 \\
RS 25 & 1.8 & 5.4 & 12.7 & 43.8 & 36.3 & 4.07 & .931 \\
RS 26 & 1.0 & 5.2 & 15.3 & 41.9 & 36.5 & 4.08 & .902 \\
RS 27 & 6.9 & 13.7 & 10.7 & 37.1 & 31.7 & 3.73 & 1.232 \\
RS 28 & 4.4 & 10.1 & 12.1 & 37.9 & 35.5 & 3.90 & 1.127 \\
RS 29 & 0.4 & 2.0 & 8.9 & 49.6 & 39.1 & 4.25 & .732 \\
\hline Total of RS & & & & & 4.17 & .819 \\
\hline Total of LC & & & & & & \\
\hline
\end{tabular}

Note: LC = Leadership Competencies; PS = Personal Skills; RS = Required Skills

The emphasis here is on the respondents' opinion regarding the ALC. Their responses were measured based on the five-point Likert scale. A high score for a particular item refers to a higher level of respondents' agreement. The overall mean score also indicates the level of respondents' understanding. The total mean score refers to a specific interpretation of the agreement level. Table 4 below shows the interpretation of mean score.

Table 4: Interpretation of Mean Score

\begin{tabular}{cc}
\hline Mean Score & Interpretation \\
\hline $1.00-1.80$ & Very Low \\
$1.81-2.60$ & Low \\
$2.61-3.20$ & Medium \\
$3.21-4.20$ & High \\
$4.21-5.00$ & Very High \\
\hline
\end{tabular}

Source: Hamzah, Juraime, \& Mansor, 2016; Khumsikiew, Donsamak, \& Saeteaw, 2015.

The results above indicate that the overall mean score of the PS was 4.32, with a standard deviation of .700. This total score (4.32) ranges between 4.21-5.00, which indicates a very high mean score as suggested by Hamzah et al. (2016) and Khumsikiew et al. (2015). The overall mean score of the RS was 4.17, with a standard deviation of .819. This total score (4.17) ranges from 3.21-4.20, which indicates a high mean score. In general, the results above show that the overall mean score of the LC was 4.25, with a standard deviation of .477. This total score of (4.25) ranges from 4.215.00 , which indicates a very high mean score. Accordingly, the findings show that the respondents agreed that the level of academic leaders in selected higher education institutions was a very high level of competencies in terms of a very high level of the PS and high level of the RS. Thus, according to the respondents, the academic leaders in selected Saudi Higher Education had a very high level of personal skills and a high level of required skills that reflect on a very high level of leadership competencies. 


\section{Gender Difference and Academic Leadership Competencies}

\section{i. Gender Difference Based on Personal Skills (PS)}

To achieve the second objective regarding gender differences of the ALC in terms of their PS, hypothesis $\mathrm{H}_{1}$ was tested. An independent sample t-test was applied to test $\mathrm{H}_{1}$ and assessed the differences in the mean score of the ALC in terms of their PS based on gender at the 0.05 alpha's level. Table 5 shows the results from the Group Statistic of Gender for the ALC in terms of their PS.

Table 5: Group Statistic for PS

\begin{tabular}{cccccc}
\hline & Gender & N & Mean & Std. Deviation & Std. Error Mean \\
\hline \multirow{2}{*}{ PS } & Male & 228 & 4.3991 & .39180 & .02595 \\
& Female & 268 & 4.2817 & .52391 & .03200 \\
\hline
\end{tabular}

The table 5 above shows the number of respondents in each group. It appears that 228 of respondents were male, while 268 were female. The results also indicated that there was a significant difference in the mean score of the PS for academic leaders based on gender. The mean score for male academic leaders $(M=4.3991, S D=.39180)$ was higher than female academic leaders $(M=4.2817, S D=.52391)$. Table 6 below also includes more details regarding examining the assumptions by the independent sample t-test.

Table 6: The Independent Sample t-test

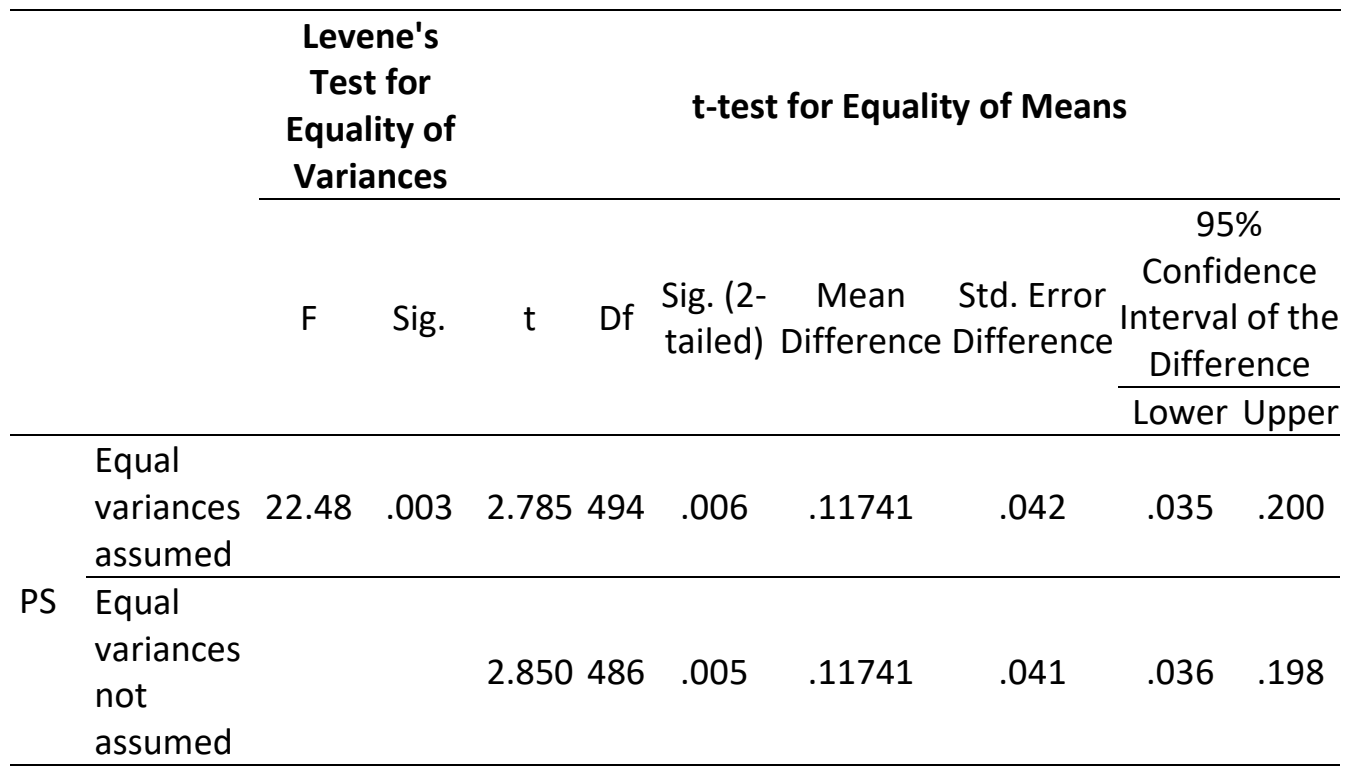

Table 6 above presents the results of the independent sample t-Test. To check the tvalue and its significance, the Levene's test should be considered. As stated by Pallant (2013), if the significance value of Levene's Test is higher than 0.05 , the section of equal variances assumed should be considered; otherwise, the line of equal variances that is not assumed must be considered. Based on this assumption, the results in the table above indicate that the significance value for gender is $(.000)$, which is lower than 0.05 . Thus, the line of assumption on equal variances that is not assumed must be considered $(T=2.850 ; \mathrm{df}=486)$. To check the differences between groups, the value of $t$-test for equality of means should be checked (Pallant, 2013). If the value of 
t-test is equal or lower than 0.05 , this indicates that there is a significant gender difference in the mean score.

But, if this value is higher than 0.05 , this suggests that there is no significant difference in the mean score (Pallant, 2013). Based on this discussion, the value in Table 6 above indicates that the significance (2-tailed) for the equal variances that is not assumed is (.005), which is lower than 0.05 . This finding implied that there is a significant gender difference in the mean score. It indicates that male academic leaders have more competencies in terms of personal skills than female academic leaders. Therefore, the conclusions of independent sample t-test showed that there is a significant gender difference in the mean score of the ALC in terms of their PS. Male academic leaders have more leadership competencies (personal skills) than female academic leaders. Thus, the first hypothesis $H_{1}$ can be accepted.

\section{ii. Gender Difference Based on Required Skills (RS)}

Hypothesis $\mathrm{H}_{2}$ was also tested to achieve the second objective and investigated the differences of the ALC in terms of their RS. An independent sample t-test was applied to test $\mathrm{H}_{2}$ and assessed the differences in the RS mean score of academic leaders based on gender at the 0.05 alpha's level. Table 7 presents the results of Group Statistic of Gender for the ALC in terms of their RS.

Table 7: Group Statistic for RS

\begin{tabular}{cccccc}
\hline \multirow{4}{*}{ RS } & Gender & $\mathbf{N}$ & Mean & Std. Deviation & Std. Error Mean \\
\cline { 2 - 6 } & Male & 228 & 4.2262 & .49027 & .03247 \\
& Female & 268 & 4.1248 & .57754 & .03528 \\
\hline
\end{tabular}

Table 7 above shows that 228 respondents were male, whereas 268 were female. Besides, there was a significant difference in the mean score of the RS for academic leaders based on gender. The mean score for male academic leaders $(M=4.2262, S D=$ $.49027)$ was higher than female academic leaders $(M=4.1248, S D=.57754)$. Table 8 below presents the assumptions via the independent sample t-test.

Table 8: The Independent Sample t-test

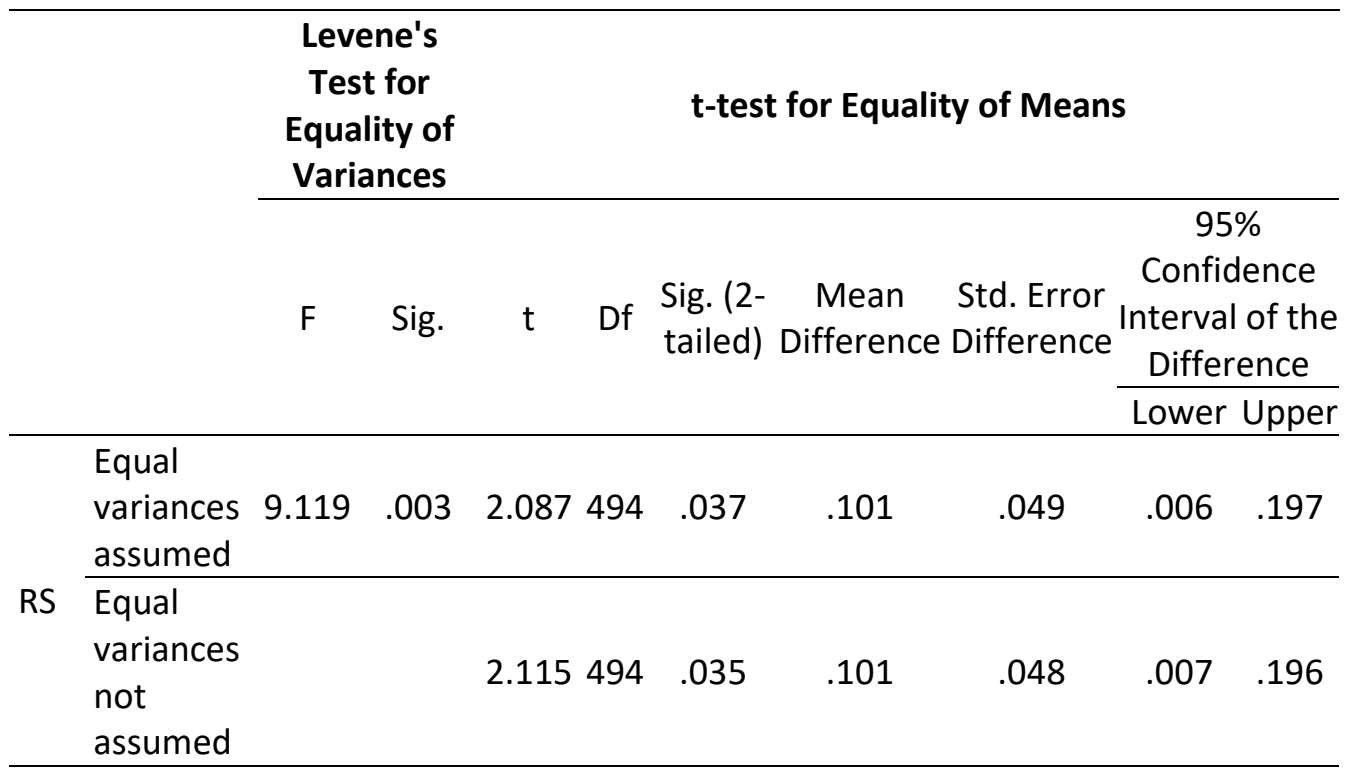


The findings in Table 8 above show that the significance value of the Levene's Test for gender is (.003), which is lower than 0.05 . Therefore, as stated earlier, the line on the assumption of equal variances that is not assumed should be considered $(T=2.115$; $\mathrm{df}=494)$. The differences between the groups have been checked based on testing the value of $t$-test for the equality of means. If the value of t-test is equal or lower than 0.05 , this indicates that there is a significant gender difference in the mean score. However, if this value is higher than 0.05 , it shows that there is no significant difference in the mean score. Based on that, the value shown in Table 8 above on the significance (2-tailed) of the equal variances that is not assumed is (.035), which is lower than 0.05 . This finding of (.035) indicated that there is a significant gender difference in the mean score. The finding also shows that male academic leaders have more competencies in terms of the required skills than female academic leaders. Therefore, the second hypothesis $\mathrm{H} 2$ can be accepted and referred to the independent sample t-test, which clarified that there is a significant gender difference in the mean score of the ALC in terms of their RS. Male academic leaders have more competencies (required skills) than female academic leaders in higher education.

\section{DISCUSSION}

Based on the perspectives of faculty members, the findings imply that the academic leaders had a very high level of leadership competencies in the SSHEls. The academic leaders had a very high level of the PS and the RS, which were identified by this study. Clark (2016) cited that competencies of leadership cover different skills of leadership, including the PS and the RS. Therefore, the findings indicate that academic leaders had a very high level of competencies in terms of having a very high level of the PS and the RS. The academic leaders had a very high level of the PS that covers professionalism, teamwork, self-direction, interpersonal skills, problem-solving skills, business acumen financial skills, flexibility, managing client relationships, building desired relationships, and communication skills. In addition, the findings also indicate that academic leaders have a very high level of the RS. The RS of leaders cover skills in leading a team, team creation, assessing diverse situations accurately and quickly, implementing policies of employee involvement, high skills of project management, training subordinates, a visioning process, teaching assistants, promoting conflict resolution, and leadership abilities.

Evidently, the finding implied that the academic leaders have a very high level of competencies which presents a very high level of their personal and required skills. This finding is in line with the results of Albutti (2014) who clarified that academic leaders at Ha'il University, a Saudi Higher Education institution, had a very high degree of the LC. The finding was also correlated with the study of Shahmandi et al. (2012) who indicated that there is no low level of competencies of leadership at Malaysian research universities. Shahmandi et al. (2012) stated that the LC was ranked from high to moderate in research universities in Malaysia. The current findings are also supported by the results of Trettel (2011) in terms of no low level of the ALC in higher education. The study by Trettel (2011) also found that the level of competencies that presents leadership skills for the administrators, at American community colleges, were above average. When we compared the previous findings for Shahmandi et al. (2012) and Trettel (2011), we can find that the ranking differs between these countries. However, the previous findings and the current finding confirmed that there is a positive level of the ALC in higher education. 
Nevertheless, the current finding is in contrast with the findings of Alhamdi (2000) who indicated that the level of academic leadership skills (competencies) was low at Sanaa University in Yemen. Also, the studies found that there is a low level of LC which suggested that it is vital to provide guidelines, clear vision, a systemic approach or to establish development programmes regarding the roles and responsibilities of academic leaders in higher education. The guidance and the systemic approach will enhance the skills and competencies of academic leaders and reflect positive outcomes as mentioned by Alhojeli (2010), Smith and Wolverton (2010), and Spendlove (2007).

As noted above, the current finding concludes that academic leaders at selected Saudi Higher Education institutions had a very high level of $L C$. This finding is in line with the findings of Albutti (2014), who conducted a similar study at a similar environment. Both studies confirmed that academic leaders have a very high level of competencies in selected Saudi Higher Education Institutions. This conclusion refers to that selected Saudi educational institutions already have useful guidelines, strong systematic approaches or active development programmes that reflected a very high level of the ALC.

The results also indicate that there is a significant gender difference in the mean score of the ALC in terms of their PS and RS. The current findings also show that male academic leaders have more leadership competencies in terms of their personal and required skills than female academic leaders. This is in line with the results of Arditi et al. (2013), Connerley et al. (2008), Nieva and Gutek (1981), and Samuel and Mokoaleli, (2017) who clarified that there is a significant gender difference in LC in terms of male leaders who are more competent than female leaders. However, the current finding is in contrast with what was stated by Donnell and Hall (1980), and Powell (1990) who pointed out that there are no significant gender differences in LC between male and female leaders.

In short, the respondents in this study have a very high level of agreement regarding the level of the ALC in selected Saudi Higher Education. They have a very high level of agreement regarding the two factors of the PS and the RS, which created a very high level of $L C$ in higher education. This finding implies that academic leaders have a very high level of LC which enables them to lead effectively, and to achieve the required outcomes of higher education. Although the findings indicated that academic leaders have a very high level of competencies, male academic leaders have more competencies than female academic leaders in Saudi Higher Education institutions.

\section{CONCLUSION AND RECOMMENDATIONS}

The findings illustrate that the faculty members of the selected Saudi institutions of higher learning had a very high level of agreement regarding the level of leadership competencies. The findings confirmed that academic leaders have a very high level of $\mathrm{LC}$ covering their personal and required skills of leaders. The findings also indicate that there is a significant gender difference in the ALC in terms of male academic leaders who have more LC compared to female academic leaders.

The current findings contributed to the body of literature in terms of clarifying that there are no low-level-academic leadership competencies in tertiary education. The findings also confirmed with what was stated in the literature in terms of male leaders being more at the competency level compared to female leaders. Therefore, leadership development programmes need to be established to ensure the 
effectiveness of female academic leaders in higher education, to enhance their personal and required skills. Besides, the Leadership Competency Model developed by Clark (2016) is a useful one that can be applied in the context of higher education. The current study will be beneficial for higher education in terms of providing evidence on the level of LC in selected Saudi higher education institutions, and gender differences of the ALC in higher education.

Accordingly, future studies need to identify factors that contribute to enhancing the LC of academic leaders in tertiary education. It is also recommending the investigation of factors that made male leaders more leadership competent (LC) than female leaders in higher education. Higher education institutions are recommended to establish useful guidelines, systematic approaches, and to develop different programmes that enhance the ALC, especially for female academic leaders. Future studies are also encouraged to examine the relationship between the level of ALC and performance in higher education institutions.

\section{REFERENCES}

Adams, D., \& Md Yusoff, N. N. (2019). The rise of leadership for learning: Conceptualization and practices. International Online Journal of Educational Leadership, 3(1), 1-3.

Albutti, A. M. (2014). Leadership competencies of the academic heads of departments at Ha'il University. Journal of Educational \& Psychological Sciences, 15(2), 629662.

Alfraih, F. (2014). The role of transformational leadership in influencing students outcomes in public secondary schools in Kuwait (Doctoral thesis). Available from ProQuest Dissertations and Theses Global. (Record No. 10078449).

Alhojeli, N. (2010). The opinions of the departments' heads at Thamar University toward their academic and administration's tasks. Damascus University Journal, 26, 59-92.

Alhamdi, F. (2000). Clarity and difficulty of goals and their relationship to the performance of the head of scientific departments at the university of Sana. (Unpublished masters thesis), University of Kufa, Iraq.

Almaki, S. H., Silong, A. D., Idris, K., \& Abd Wahat, W. (2016). Effective leadership practices of Muslim women academic leaders. The Social Sciences, 11(9), 2217-2229.

Al-Safran, E., Brown, D., \& Wiseman, A. (2014). The effect of principal's leadership style on school environment and outcome. Research in Higher Education Journal, 22, 1-19.

Alshayea, A. (2012). Improvement of the quality assurance in Saudi higher education. Procedia - Social and Behavioral Sciences, 47, $2234-2236$.

Arditi, D., Gluch, P. \& Holmdahl, M. (2013). Managerial competencies of female and male managers in the Swedish construction industry. Construction Management and Economics, 31(9), 979-990.

Balwant, P. T. (2016). Transformational instructor-leadership in higher education teaching: A meta-analytic review and research agenda. Journal of Leadership Studies, 9(4), 20-42.

Bartlett, M. S. (1954). A note on the multiplying factors for various $\chi 2$ approximations. Journal of the Royal Statistical Society, 16(2), 296-298.

Bass, B. M., \& Avolio, B. J. (2004). Multifactor Leadership Questionnaire: Manual and sampler set (3rd ed.). Menlo Park, CA: Mind Garden, Inc. 
Bass, B. M., \& Avolio, B. J. (1994). Improving organizational effectiveness through transformational leadership. Thousand Oaks, CA: Sage Publications, Inc.

Bellibas, M. S., Özaslan, G., Gümüs, E., \& Gümüs, S. (2016). Examining department chairs' needs in performing academic leadership in Turkish universities. Egitim ve Bilim, 41(184), 91-103.

Carless, S. A., Wearing, A. J., \& Mann, L. (2000). A short measure of transformational leadership. Journal of Business and Psychology, 14(3), 389-405.

Chua, Y. P. (2016). Mastering research methods (2nd ed.). Shah Alam, Selangor: McGraw-Hill Education.

Clark, D. R. (2016). Leadership competency model. Retrieved January 4, 2018, from http://www.nwlink.com/ donclark/hrd/case/chart1.html

Connerley, M. L., Mecham, R. L., \& Strauss, J. P. (2008). Gender differences in leadership competencies, expatriate readiness, and performance. Gender in Management: An International Journal, 23(5), 300-316.

Creswell, J. W., \& Creswell, J. D. (2017). Research design: Qualitative, quantitative, and mixed methods approaches (5th ed.). Thousand Oaks, CA: Sage Publications, Inc.

Karavidić, M. C., Karavidić, S., \& Vujičić, S. (2016). Business education and social skills to leadership competencies. International Review, 1-2, 38-45.

Day, C., Gu, Q., \& Sammons, P. (2016). The impact of leadership on student outcomes: How successful school leaders use transformational and instructional strategies to make a difference. Educational Administration Quarterly, 52(2), 221-258.

Donnell, S. M., \& Hall, J. (1980). Men and women as managers: A significant case of no significant difference. Organizational Dynamics, 8(4), 60-77.

Eklund, K. E., Barry, E. S., \& Grunberg, N. E. (2017). Gender and leadership. In A. Alvinius (Ed.), Gender differences in different contexts (pp. 129-150). Retrieved from https://www.intechopen.com/books/gender-differences-indifferent-contexts

Gmelch, W. H. (2013). The development of campus academic leaders. International Journal of Leadership and Change, 1(1), 25-35.

Hair, J. F., Hult, G. T. M., Ringle, C. M., \& Sarstedt, M. (2017). A primer on partial least squares structural equation modeling (PLS-SEM) (2nd ed.). Thousand Oaks, CA: Sage Publications, Inc.

Hallinger, P., \& Hammad, W. (2019). Knowledge production on educational leadership and management in Arab societies: A systematic review of research. Educational Management Administration \& Leadership, 47(1), 20-36.

Hammad, W., \& Hallinger, P. (2017). A systematic review of conceptual models and methods used in research on educational leadership and management in Arab societies. School Leadership \& Management, 37(5), 434-456.

Mohd Hamzah, M. I., Juraime, F., \& Mansor, A. N. (2016). Malaysian principals' technology leadership practices and curriculum management. Creative Education, 7, 922-930.

Kaiser, H. F. (1974). An index of factorial simplicity. Psychometrika, 39(1), 31-36.

Krejcie, R. V., \& Morgan, D. W. (1970). Determining sample size for research activities. Educational and Psychological Measurement, 30(3), 607-610.

Khumsikiew, J., Donsamak, S., \& Saeteaw, M. (2015). A model of small-group problembased learning in pharmacy education: Teaching in the clinical environment. The IAFOR Journal of Education, 3(2), 95-108. 
Leithwood, K., Patten, S., \& Jantzi, D. (2010). Testing a conception of how school leadership influences student learning. Educational Administration Quarterly, 46(5), 671-706.

Majeed, N., Mohd Nor, M. N., \& Mohd Mustamil, N. (2017). Exploring relationship between transformational leadership and organizational citizenship behaviors through lens of workplace spirituality. International Online Journal of Educational Leadership, 1(1), 5-33.

McClelland, D. C. (1973). Testing for competence rather than for "intelligence". American Psychologist, 28(1), 1-14.

McDaniel, E. A. (2002). Senior leadership in higher education: An outcomes approach. Journal of Leadership and Organisational Studies, 9(2), 80-88.

Ngowi, A. (2017). Recruiting and developing academic leaders. In M. E. Auer, \& K. -S. Kim (Eds.), Advances in Intelligent Systems and Computing (pp. 82-91). Cham, Switzerland: Springer

Nieva, V. F. \& Gutek, B. A. (1981). Women and work: A psychological perspective. New York: Praeger.

Northouse, P. G. (2016). Leadership: Theory and practice (7th ed.). Thousand Oaks, CA: Sage Publications, Inc.

Pallant, J. (2013). SPSS survival manual: A step by step guide to data analysis using IBM SPSS (5th ed.). Berkshire, England: McGraw-Hill Education.

Pina, R., Cabral, I., \& Alves, J. M. (2015). Principal's leadership on students`outcomes. Procedia-Social and Behavioral Sciences, 197, 949-954.

Powell, G. N. (1990). One more time: Do female and male managers differ? Academy of Management Executive, 4(3), 68-75.

Radwan, O., Abdul Razak, A. Z., \& Ghavifekr, S. (2020). The mediating effect of organisational culture on academic leadership skills and students' skill-based learning outcomes in Saudi higher education. MOJEM: Malaysian Online Journal of Educational Management, 8(1), 39-57.

Rafique, G. M. (2014). Information literacy skills of faculty members: A study of the University of Lahore, Pakistan. Library Philosophy and Practice, 1-23.

Royal Commission for Jubail \& Yanbu. (2019). Jazan City for primary and downstream industries report. Retrieved from https://www.rcjy.gov.sa/enUS/Jazan/Pages/Jazan-City-for-Primary-and-Downstream-IndustriesReport.aspx

Samuel, O. M., \& Mokoaleli, I. (2017). Analysis of gender and leadership role competencies, perceptions and stereotypes in an organisational context. South African Journal of Business Management, 48(2), 55-66.

Saudi Ministry of Education. (2019). Higher education. Retrived January 1, 2019, from https://www.moe.gov.sa/en/Pages/default.aspx

Seemiller, C. (2016). Leadership competency development: A higher education responsibility. New Directions for Higher Education, 174, 93-104.

Shahmandi, E., Silong, A. D., \& Ismail, I. A. (2012). Level of competencies, gender and leadership effectiveness in a research university. Management Research and Practice, 4(1), 63-73.

Smith, Z. A., \& Wolverton, M. (2010). Higher education leadership competencies: Quantitatively refining a qualitative model. Journal of Leadership \& Organizational Studies, 17(1), 61-70.

Spencer, L. M., \& Spencer, S. M. (1993). Competence at work: Models for superior performance. New York: John Wiley \& Sons, Inc. 
Spendlove, M. (2007). Competencies for effective leadership in higher education. International Journal of Educational Management, 21(5), 407-417.

Sultana, U. S., Darun, M. R., \& Liu, Y. (2015). Transactional or transformational leadership: Which works best for now? International Journal of Industrial Management, 1, 1-9.

Sydänmaanlakka, P. (2003). Intelligent leadership and leadership competencies: Developing a leadership framework for intelligent organization (Doctoral dissertation, Helsinki University of Technology, Finland). Retrieved from https://core.ac.uk/download/pdf/80701048.pdf

Tavakol, M., \& Dennick, R. (2011). Making sense of Cronbach's alpha. International Journal of Medical Education, 2, 53-55.

Tomal, D. R., \& Jones, K. J. (2015). A comparison of core competencies of women and men leaders in the manufacturing industry. The Coastal Business Journal, 14(1), 13-25.

Trettel, B. S. (2011). An assessment of leadership competencies in Pennsy/vania's community colleges (Doctoral dissertation, University of Pittsburgh, United States). Retrieved from http://dscholarship.pitt.edu/6220/1/disseration_btrettel_11_20_11.pdf

Vazirani, N. (2010). Competencies and competency model: A brief overview of its development and application. SIES Journal of Management, 7(1), 121-131.

Walumbwa, F., Avolio, B., Gardner, W., Wernsing, T., \& Peterson, S. (2008). Authentic leadership: Development and validation of a theory-based measure. Journal of Management, 34(1), 89-126.

Yukl, G. A. (2013). Leadership in organisations (8th ed.). Upper Saddle River, NJ: Pearson. 